\title{
Relation of median nerve to brachial artery: variations, embryological basis and clinical significance
}

\author{
Sudarshan Babu K G ${ }^{1}$, Shubha $\mathrm{R}^{2}$, Mekala $\mathrm{D}^{2}$, Lalitha $\mathrm{C}^{2}$, Jeyanthi $\mathrm{K}^{2}$ \\ ${ }^{I}$ Department of Surgery, Kempegowda Institute of Medical Sciences, Bangalore, India \\ ${ }^{2}$ Department of Anatomy, Kempegowda Institute of Medical Sciences, Bangalore, India
}

\begin{abstract}
Brachial artery is the main artery supplying the upper limb. Variations in brachial artery are so many that it becomes a rule rather than an exception. A study was done to note the variations in the relation of median nerve to brachial artery. A total of 95 upper limbs (51 Right, 44 Left), with a mean arm length of 30.82 $\mathrm{cms}$, were studied. In 11 of the limbs (11.57\%) median nerve was noted to course posterior (deep) to brachial artery (Superficial Brachial Artery, SBA). Out of these 11 limbs, 6 (54.54\%) belonged to right side and 5 $(45.45 \%)$ belonged to left side. In 9 of these limbs $(81.81 \%)$, median nerve coursed posterior to brachial artery in the middle $1 / 3^{\text {rd }}$ of the arm, whereas in 2 of the limbs (18.18\%), crossing took place at the junction of middle and lower $1 / 3^{\text {rd }}$ of the arm. In 5 (45.45\%) of these limbs brachial artery terminated normally, whereas in the remaining 6 (54.54\%) trifurcation of brachial artery was noted. A significant association $\left(\chi^{2}=29.971, P=0.003\right)$ was found between the type of terminal branches of brachial artery and level of crossing of median nerve in relation to arm segment. This anatomical knowledge of variations in the relation of median nerve to brachial artery is of great clinical significance to general surgeons, vascular surgeons and orthopaedicians and helps in preventing iatrogenic injuries.
\end{abstract}

Keywords: Brachial artery, level of crossing, median nerve, superficial brachial artery, variations.

\section{Introduction}

The brachial artery, a continuation of the axillary, begins at the distal (inferior) border of the tendon of teres major and ends about a centimeter distal to the elbow joint by dividing into radial and ulnar arteries. The brachial artery is wholly superficial, covered anteriorly only by skin, superficial and deep fasciae. The median nerve crosses it lateromedially near the distal attachment of coracobrachialis. Rarely, the median nerve crosses behind, and not in front of, the brachial artery [1].

The arterial pattern of upper limb show a wide range of variations and these variations have been given a lot of importance in anatomical literature. The brachial artery coursing in front of rather than behind the median nerve is called as superficial brachial artery (SBA) [2]. Presence of variant vessels may increase the risk of complications during some procedures, but it may be beneficial for others e.g., a variant superficial vessel is easily approachable during catheterization [3]. Knowledge of variations helps to avoid brachial plexus lesions during surgeries and is also important in surgical management of nerve injuries. Hence, knowledge of these variations is of importance not only because of the diagnostic and therapeutic interventions involving the upper limb arteries, but also due to various surgical and reconstructive procedures involving this area due to frequent injuries.

Even though a number of case reports have been reported, not many studies have been done regarding variations in relation of median nerve to brachial artery. Hence the present study was conducted to observe the variations in relation of median nerve to brachial artery and these variations are correlated with arm length and the type of terminal branches of brachial artery. The authors have also tried to provide an embryological basis for the variations and their clinical implications.

\section{Materials And Methods}

A total of 95 cadaver upper limbs (51 right and 44 left), irrespective of sex, were examined in the Department of Anatomy, Kempegowda Institute of Medical Sciences, Bangalore. The length of the arm was noted down by measuring the distance between the summit of the acromion of scapula and the lateral epicondyle of the humerus. The arm was divided topographically into three equal segments. The arm and cubital fossa were dissected to expose brachial artery and median nerve as per Cunningham's manual of practical Anatomy [4]. The relation of median nerve to brachial artery was noted down. The level of median nerve crossing brachial artery in relation to the segment of the arm was observed and the distance between the level of crossing of median nerve and the intercondylar line was measured in cms. Terminal branches of brachial artery were noted down.

Statistical analysis of the data was done to get the percentage, mean and standard deviation (SD). Difference in mean of two variables was analyzed by doing ' $Z$ ' test. 'Chi squared test' was done to determine 
the association between two variables. Also correlation between two variables was determined by doing 'Spearman's rank correlation'. The results obtained were considered statistically significant when $\mathrm{P}<0.05$.

\section{Results}

Among the 95 upper limbs studied, the arm length varied between 26 to $36 \mathrm{cms}$, with a mean arm length of $30.82 \mathrm{cms}$. When the relation of median nerve to brachial artery was observed, it coursed superficial to artery in $88.42 \%$ of the limbs ( 45 right \& 39 left) and deep to the artery i.e., SBA was seen in $11.57 \%$ of limbs (6 right \& 5 left) (Figure 1). No significant association was found when this was compared between the two sides $\left(\chi^{2}=0.004, \mathrm{P}=0.951\right)($ Table 1$)$.

Next, the distance between the level of median nerve crossing brachial artery and the intercondylar line was measured. The minimum distance of $0 \mathrm{cms}$ i.e., median nerve crossing brachial artery at the intercondylar line, was noted in a right upper limb with arm length $33 \mathrm{cms}$. The maximum distance noted was $18 \mathrm{cms}$ in case of a right upper limb with arm length $31 \mathrm{cms}$. Statistically no significant difference $(\mathrm{P}>0.05)$ was found when the mean levels of median nerve crossing superficial or deep to brachial artery were compared on the two sides (Table 2). No correlation was found between the arm length and the level of crossing of brachial artery by median nerve.

When the arm segment was considered, in 82 limbs $(86.31 \%)$ median nerve crossed brachial artery in the middle $1 / 3^{\text {rd }}$ of the arm, in 9 limbs $(9.47 \%)$ at the junction of middle and lower $1 / 3^{\text {rd }}$ and in 4 limbs $(4.21 \%)$ in the lower $1 / 3^{\text {rd }}$ of the arm. Out of the 11 limbs with SBA, crossing occurred in the middle $1 / 3^{\text {rd }}$ of the arm in 9 of the limbs $(81.81 \%)$ and in the remaining $2(18.18 \%)$ at the junction of middle and lower $1 / 3^{\text {rd }}$ of the arm. In all the 4 limbs, where crossing took place in the lower $1 / 3^{\text {rd }}$ of the arm, the median nerve was superficial to the artery. When the crossing in relation to arm segment was compared between the two types of crossing (superficial \& deep), it was found that there was no significant association $\left(\chi^{2}=1.549, \mathrm{P}=0.461\right)$ (Table 3 ).

When termination of brachial artery was considered, it was bifurcating in $72.6 \%$ of limbs and trifurcation was noted in $26.3 \%$ of the limbs. Out of the 11 limbs with superficial brachial artery, 5 (45.45\%) terminated normally, whereas in the remaining $6(54.54 \%)$ ( 2 right \& 4 left), trifurcation of brachial artery was noted. Statistically significant association $\left(\chi^{2}=29.971, \mathrm{P}=0.003\right)$ was found between the type of terminal branches and the level of crossing of median nerve in relation to arm segment (Table 4).

\section{Discussion}

Anomalies of the forelimb arteries are very common. This is because of their multiple and plexiform sources of origin, the temporal succession of emergence of principal arteries, anastomosis and periarterial network \& functional dominance followed by regression of some paths [5]. Persistence of embryological vessels may be the basis of SBA. The SBA is a consistent embryonic vessel that plays an important role in the normal arterial morphogenesis of the upper limb [6]. This may be due to haemodynamic persistence of superficial system over deep system at the origin of SBA. Genetic influences are deemed to be prevalent causes of such variation, although factors like foetal position in utero, first limb movement or unusual musculature cannot be excluded. [7]. So anomalies of brachial artery are frequent, due to complex \& dynamic processes involved in its development.

Most of the earlier reports of SBA, by both large sample studies and case reports, are associated with 2 brachial arteries in the arm where one is superficial and the other is deep to the median nerve. But in the present study, a single artery in the arm with a superficial course in relation to median nerve was considered as SBA. Hence the results of the present study could not be compared with many of the previous studies. Also the present study was done on upper limbs of the 2 sides, irrespective of sex. Hence variations with respect to gender reported by some studies could not be compared with the present study.

In the present study, SBA was observed in $11.57 \%$ of the limbs (11 out of 95 limbs). Out of these 6 belonged to right side and 5 belonged to left side. In a study done in 192 cadavers (91 males \& 101 females), total incidence of SBA was 19 of 384 upper limbs (4.9\%), which is lower than that observed in the present study. Out of these, $11(5.7 \%)$ belonged to right side and $8(4.2 \%)$ belonged to left side. This correlates with the present study where SBA was more on the right than the left side. But in both the studies, the Chi-Squared test did not show statistically significant difference between right and left sides $(\mathrm{P}>0.05)$. They have also reported that the brachial artery adopted its course superficial to the median nerve, crossing below the median nerve roots in 12 limbs (63.2\%), which correlate with most of the previous studies. It also correlates with the present study where the superficial course is observed in the middle $1 / 3^{\text {rd }} \&$ also at the junction of middle and lower $1 / 3^{\text {rd }}$ of the arm (below the median nerve roots). They have concluded that the incidence of SBA varies from 3.6 to $9.6 \%$, is more frequent in males and on the right side, and a unilateral presence is more common. But these results were not statistically significant. They have quoted Miller (1939) that "a combination of nerve and arterial variations is extremely difficult to analyse or classify" [8]. 
In a study conducted on 50 upper limbs of 25 cadavers ( 19 males, 6 females), SBA was observed in 3 limbs (6\%). Out of these 3 limbs, in one female right limb, the brachial artery was found crossing superficial to median nerve from medial to lateral side in the middle $1 / 3^{\text {rd }}$ of the arm. They have stated that Miller (1939) believed that SBA is an atavistic condition (retention of a primitive pattern), as the main brachial artery crossing superficial to median nerve is the usual arrangement in the primates. They have noted that different studies have reported varied prevalence of SBA. An incidence of SBA similar to their study was found by Poirier (1886), Linell (1921), McCormack et al (1953) and Kapur et al (2000). A lower incidence than theirs was reported by various studies and the incidence ranged from $0.2-3.0 \%$ whereas a higher incidence reported by few other studies ranged between $11.9 \%$ and $25.0 \%$ [9]. According to this, the incidence in the present study belongs to the higher incidence range. So there is a difference in the incidence between the two studies, even though the population studied was similar and criteria for designating SBA were same. This difference could be due to difference in the sample size between the two studies.

Another study was done on 130 upper limbs (61 males \& 69 females) belonging to Czech population, to note the branching pattern of axillary artery with accent on SBA. The incidence of SBA in this study was 5\% which is much lower than the present study. The authors have noted an interesting phenomenon which could be traced throughout the years of the studies. Originally SBA was observed in only $1-3 \%$ of cases; later studies in 1940 s reported a $12-25 \%$ incidence whereas in the last 10 years, the incidence is documented to be only $5-6 \%$. They have attributed the reasons for this sinusoid characteristic of the SBA incidence to new specification guidelines, classification of the variations \& melioration in study methods, which have been improved due to conclusion of the previous findings and observations [10].

None of the other studies have reported any association between crossing of median nerve in relation to arm segment and the terminal branches of brachial artery, but a significant association was found in the present study. Associated variations are important for general, vascular \& orthopaedic surgeons when they need to expose wider areas for better accessibility during surgeries. Also in the present study 2 things were observed in limbs where median nerve crossed brachial artery in the lower $1 / 3^{\text {rd }}$ of the arm - neither SBA nor trifurcation of brachial artery was observed in all these limbs. Also it was noted that when considered individually, both SBA and trifurcation were more on the right side compared to the left, but a combination of the two was found to be more on the left side (Left- $4.21 \%$, right- $2.10 \%$ ). But these results were not statistically significant.

Brachial artery, while crossing over the median nerve, can lay over it for some distance and compress the nerve. The diagnosis of this condition could be confusing because the symptoms resemble radiculopathy or carpal tunnel syndrome [11]. Also in cases of SBA, the superficial position of the artery renders it vulnerable to trauma. However when required, it is easily accessible for cannulation. Also SBA may be mistaken for a vein and accidental intra arterial injection of drugs may result in serious consequences. These variations cannot be evaluated even by angiographic studies. Hence awareness of these variations becomes imperative.

\section{Conclusion}

Variations in arterial pattern of upper limbs have clinical and surgical significance. Knowledge of variations in the relation between closely associated nerves and vessels is highly crucial for surgeons who need to be aware of these possibilities, especially, when they need to access or approach these areas. Hence, a thorough knowledge of superficial brachial artery and associated variations is of paramount importance to general, vascular and neurosurgeons.

\section{Acknowledgements}

The authors would like to thank the Management, the Dean and Principal and Staff, Department of Anatomy, Kempegowda Institute of Medical Sciences, Bangalore for their support and encouragement. Special thanks to Mr. Thejasvi, from Statintelligence Network for helping with the statistical analysis. The authors are grateful to authors / editors / publishers of all those articles, journals and books from where the literature for this article has been reviewed and discussed. The authors are also grateful to IOSR-JDMS editorial board members and IOSR-JDMS team of reviewers who have helped to bring out a good quality manuscript.

\section{References}

[1] Susan Standring. Gray's Anatomy (London, Elsevier Churchill Livingstone Publishers, 2008) 856.

[2] M Rodriguez-Niedenfuhr, T Vazquez, L Nearn, B Ferreira, I Parkin, J R Sanudo. Variations of the arterial pattern in the upper limb revisited: a morphological and statistical study, with a review of the literature. J. Anat. 2001. 199. pp 547-566.

[3] Shubha R, Sudarshan Babu K G, Mekala D, Jeyanthi k, Lalitha C. An Anatomical study of variations in termination of brachial artery:embryological basis and clinical application. IOSR Journal of Dental and Medical Sciences. Vol 9 Issue 1 (Jul-Aug 2013 ). $68-75$.

[4] G J Romanes. Cunningham's manual of practical Anatomy ( New York, Oxford University Press, 2005) 67-71.

[5] Chandrika Teli, Nilesh N Kate, Paarthipan N. High division and variation in brachial artery branching pattern. IOSR Journal of Dental and Medical Sciences. 2013. 3(6). 68-70.

[6] A Rodriguez-Baeza, J Nebot, B Ferreira, F Reina, J Perez, J R Sanudo, M Roig. An anatomical study and ontogenic explanation of 
23 cases with variations in the main pattern of the human brachio-antebrachial arteries. J. Anat. 1995. 187. 473-479.

[7] Ramnathan L, Nayak S R, Vinay K V, Krishnamurthy A, Prabhu L V. Coexistence of superficial brachio-ulno-radial arterial pattern and persistent median artery. J Plast Surg. 2009. 42(1). 112-114.

[8] M Rodriguez-Niedenfuhr, T Vazquez, L Nearn, B Ferreira, I Parkin \& J R Sanudo. Variations of the arterial pattern in the upper limb revisited: a morphological and statistical study, with a review of the literature. J. Anat. (2001). 199. 547-566.

[9] Patnaik V V G, Kalsey G, Singla Rajan K. Branching pattern of brachial artery - a morphological study. J. Anat. Soc. India. 2002. 51(2).176-186.

[10] David Kachlik, Marek Konarik, Vaclav Baca. Vascular patterns of upper limb: an anatomical study with accent on superficial brachial artery. Bosnian Journal of Basic Medical Sciences. 2011. 11(1). 4-10.

[11] Ragiba Zagyapan, Can Pelin, Nuket Mas. Abnormal vascular pattern in the upper limb: original image. Turkiye Klinikleri J Med Sci. 2007. 27: 807-809.

\section{TABLES}

Table 1: Distribution of type of median nerve crossing in each side

\begin{tabular}{|c|c|c|c|c|c|c|c|}
\hline \multirow{2}{*}{ Side } & \multicolumn{2}{|c|}{ Superficial } & \multicolumn{2}{|c|}{ Deep } & \multirow{2}{*}{ Total } & \multirow{2}{*}{$\chi^{2}$} & \multirow{2}{*}{ P-Value } \\
\hline & $\mathbf{n}$ & $\%$ & $\mathbf{n}$ & $\%$ & & & \\
\hline Left & 39 & $89 \%$ & 5 & $11 \%$ & 44 & \multirow{2}{*}{0.004} & \multirow{2}{*}{0.951} \\
\hline Right & 45 & $88 \%$ & 6 & $12 \%$ & 51 & & \\
\hline
\end{tabular}

Table 2: Level of crossing compared between left and right side (in each median nerve crossing)

\begin{tabular}{|c|c|c|c|c|c|c|c|c|}
\hline $\begin{array}{c}\text { Median Nerve } \\
\text { Crossing }\end{array}$ & Side & $\mathbf{n}$ & Mean & SD & $\begin{array}{l}\text { SE of } \\
\text { Mean }\end{array}$ & $\begin{array}{c}\text { Mean } \\
\text { difference }\end{array}$ & $\mathbf{Z}$ & P-Value \\
\hline \multirow{2}{*}{ Superficial } & Left & 39 & 13.27 & 1.92 & 0.31 & \multirow{2}{*}{0.593} & \multirow{2}{*}{-1.308} & \multirow{2}{*}{0.191} \\
\hline & Right & 45 & 12.67 & 2.87 & 0.43 & & & \\
\hline \multirow{2}{*}{ Deep } & Left & 5 & 14.94 & 1.46 & 0.65 & \multirow{2}{*}{1.940} & \multirow{2}{*}{-1.385} & \multirow{2}{*}{0.166} \\
\hline & Right & 6 & 13.00 & 2.21 & 0.90 & & & \\
\hline
\end{tabular}

Table 3: Crossing in relation to arm segment distributed according to median nerve crossing

\begin{tabular}{|c|c|c|c|c|c|c|c|}
\hline \multirow{2}{*}{$\begin{array}{c}\text { Crossing in relation to } \\
\text { Arm }\end{array}$} & \multicolumn{2}{|c|}{ Superficial } & \multicolumn{2}{|c|}{ Deep } & \multirow{2}{*}{ Total } & \multirow{2}{*}{$\chi^{2}$} & \multirow{2}{*}{ P-Value } \\
\hline & $\mathbf{n}$ & $\%$ & $\mathbf{n}$ & $\%$ & & & \\
\hline Middle 1/3 rd & 73 & $89 \%$ & 9 & $11 \%$ & 82 & \multirow{3}{*}{1.549} & \multirow{3}{*}{0.461} \\
\hline Junction & 7 & $78 \%$ & 2 & $22 \%$ & 9 & & \\
\hline Lower $1 / 3$ rd & 4 & $100 \%$ & 0 & $0 \%$ & 4 & & \\
\hline
\end{tabular}

Table 4: Distribution of type of branch across "Crossing in relation to arm segment"

\begin{tabular}{|c|c|c|c|c|c|c|c|c|c|}
\hline \multirow{2}{*}{ Type of branch } & \multicolumn{2}{|c|}{ Middle $1 / 3$ rd } & \multicolumn{2}{|c|}{ Junction } & \multicolumn{2}{|c|}{ Lower $1 / 3$ rd } & \multirow{2}{*}{ Total } & \multirow{2}{*}{$\chi^{2}$} & \multirow{2}{*}{ P-Value } \\
\hline & $\mathbf{n}$ & $\%$ & $\mathbf{n}$ & $\%$ & $\mathbf{n}$ & $\%$ & & & \\
\hline $\mathbf{R}+\mathbf{U}$ & 55 & $89 \%$ & 6 & $10 \%$ & 1 & $2 \%$ & 62 & \multirow{7}{*}{29.971} & \multirow{7}{*}{$0.003 *$} \\
\hline $\mathbf{U}+\mathbf{U R}$ & 1 & $50 \%$ & 0 & $0 \%$ & 1 & $50 \%$ & 2 & & \\
\hline $\mathbf{U}+\mathbf{R} \mathbf{R}$ & 1 & $50 \%$ & 0 & $0 \%$ & 1 & $50 \%$ & 2 & & \\
\hline $\mathbf{U}+\mathbf{C}$ & 2 & $67 \%$ & 0 & $0 \%$ & 1 & $33 \%$ & 3 & & \\
\hline $\mathbf{R}+\mathbf{U}+\mathbf{R} \mathbf{R}$ & 21 & $88 \%$ & 3 & $13 \%$ & 0 & $0 \%$ & 24 & & \\
\hline $\mathbf{R}+\mathbf{U}+\mathbf{U R}$ & 1 & $100 \%$ & 0 & $0 \%$ & 0 & $0 \%$ & 1 & & \\
\hline Five Branches & 1 & $100 \%$ & 0 & $0 \%$ & 0 & $0 \%$ & 1 & & \\
\hline
\end{tabular}

*denotes significant association

Figures

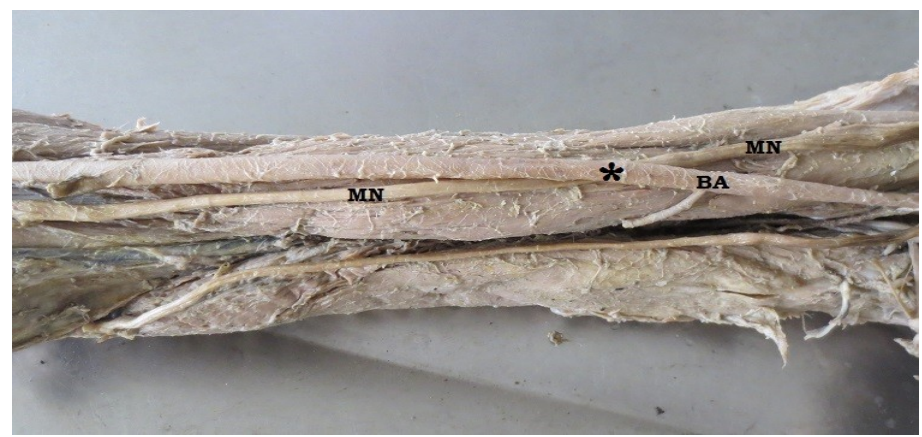

Figure 1: Right limb with superficial brachial artery. BA - brachial artery, MN - median nerve

* - Point of superficial crossing of brachial artery over median nerve 